\title{
SÉANCE DU 26 MAI 1905
}

Présidence de M. E. MALINVAUd, ViCe-Président.

M. Ed. Bureau, président, que des occupations urgentes retiennent au Muséum, s'est fait excuser de ne pouvoir assister à la séance.

M. le Secrétaire-rédacteur donne lecture du procèsverbal de la séance du 12 mai, dont la rédaction est adoptée.

M. le Président prononce l'admission de :

M. Woronoff (Georges), assistant au Jardin de Souchoum-Kale, Caucase (Russie), présenté dans la séance précédente par MI. Flahault et Daveau.

La Société a reçu deux bouquets de plantes fraîches qui seront distribuées aux membres présents à la fin de la séance.

L'un de ces bouquets, envoyé par M. Abel Albert, renferme les espèces suivantes récoltées à la Farlède (Var) : Anthyllis tetraphylla, Medicago tribuloides et pentacycla, Lotus ornithopodioides, Hippocrepis unisiliquosa, Galium cinereum et G. saccharatum, Valerianella discoidea, Phagnalon saxatile, Galactites tomentosa, Hedypnois polymorpha, Campanula Erinus, etc.

L'autre envoi est de M. Lamothe, instituteur à SaintDenis-près-Martel (Lot), et présente des espèces appartenant aux associations des causses oolithiques du Lot ou des terrains argilo-calcaires limitrophes : Nasturtium pyrenaicum, Bunias Erucago, Helianthemum salicifolium, Fumana Spachii, Dianthus brachyanthus, Trifolium maritimum, Coronilla scorpioides, Vicia bithynica, Orlaya grandiflora, Laserpitium gallicum, Convolvulus Cantabrica, Phalangium Liliago, Koleria valesiaca, Brachypodium distachyon, Bromus commutatus et B. squarrosus, Egylops triuncialis. 
C. Gatix. - UN Cas de polyembryonie Chez le musa ensete. 277

$\mathrm{M}^{\mathrm{He}}$ Marguerite Belèze a bien voulu apporter de nombreux individus de la variétélaciniée du Chelidonium majus qui seront également partagés entre les membres.

M. Gatin à la parole pour la communication suivante :

\title{
Un cas de polyembryonie chez le Musa Ensete,
}

\author{
PAR M. C. L. GATIN.
}

Parmi des graines de Musa Ensete ${ }^{1}$ que j'ai eu récemment l'occasion de faire germer, $\overline{\mathrm{il}}$ s'en est trouvé une qui a donné naissance à deux plantules parfaitement constituées.

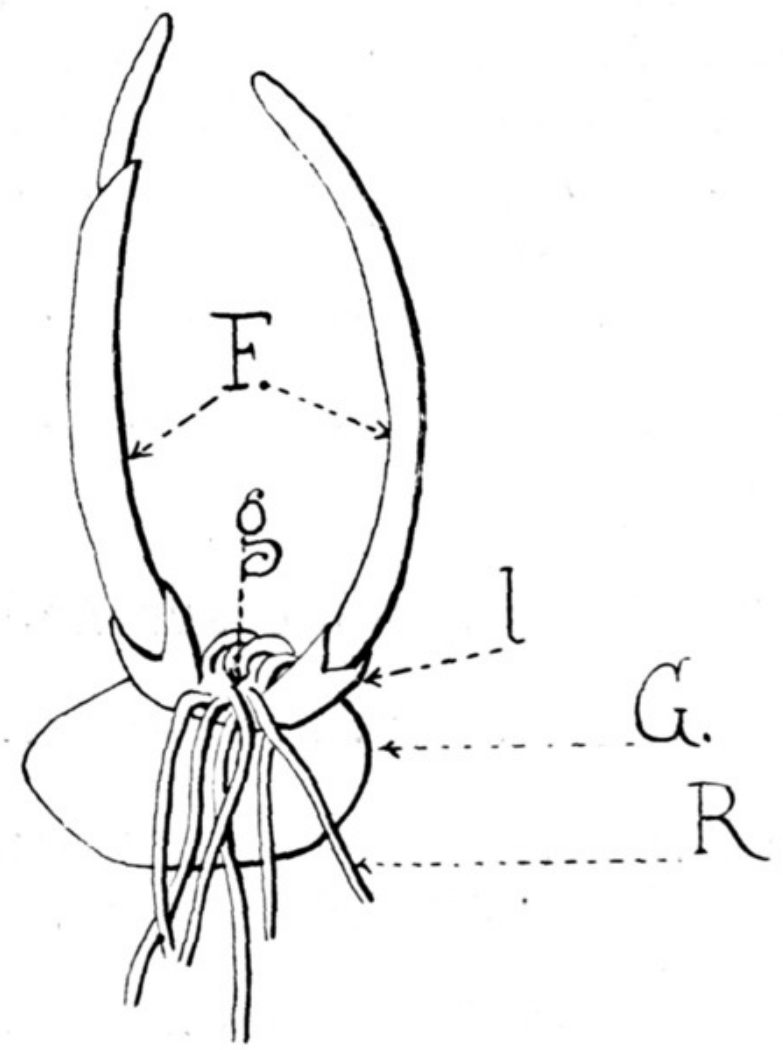

MUsa Ensete. - G, grain ; R, rasines; F, bourgeons; g, gaine colylédonaire; I, une ligule.

Ces plantules possédaient un cotylédon unique, de même forme et de même grosseur que celui des germinations normales de même àge.

1. Provenant de la maison Vilmorin-Andrieux. 


\section{$2 \mathrm{BHL}$ Biodiversity Heritage Library}

1905. "Séance Du 26 Mai 1905." Bulletin de la Société botanique de France 52, 276-277. https://doi.org/10.1080/00378941.1905.10829157.

View This Item Online: https://www.biodiversitylibrary.org/item/8674

DOI: https://doi.org/10.1080/00378941.1905.10829157

Permalink: https://www.biodiversitylibrary.org/partpdf/160514

\section{Holding Institution}

Missouri Botanical Garden, Peter H. Raven Library

\section{Sponsored by}

Missouri Botanical Garden

\section{Copyright \& Reuse}

Copyright Status: Public domain. The BHL considers that this work is no longer under copyright protection.

This document was created from content at the Biodiversity Heritage Library, the world's largest open access digital library for biodiversity literature and archives. Visit BHL at https://www.biodiversitylibrary.org. 